This item was submitted to Loughborough's Research Repository by the author.

Items in Figshare are protected by copyright, with all rights reserved, unless otherwise indicated.

\title{
Modelling and experimental studies of alternative heat treatments in Steel 92 to optimise long term stress rupture properties
}

PLEASE CITE THE PUBLISHED VERSION

PUBLISHER

(C) Maney Publishing \& Institute of Materials, Minerals and Mining

VERSION

AM (Accepted Manuscript)

LICENCE

CC BY-NC-ND 4.0

\section{REPOSITORY RECORD}

Yin, Y., Roy G. Faulkner, P.F. Morris, and P.D. Clarke. 2010. "Modelling and Experimental Studies of Alternative Heat Treatments in Steel 92 to Optimise Long Term Stress Rupture Properties". figshare. https://hdl.handle.net/2134/5975. 
This item was submitted to Loughborough's Institutional Repository (https://dspace.lboro.ac.uk/) by the author and is made available under the following Creative Commons Licence conditions.

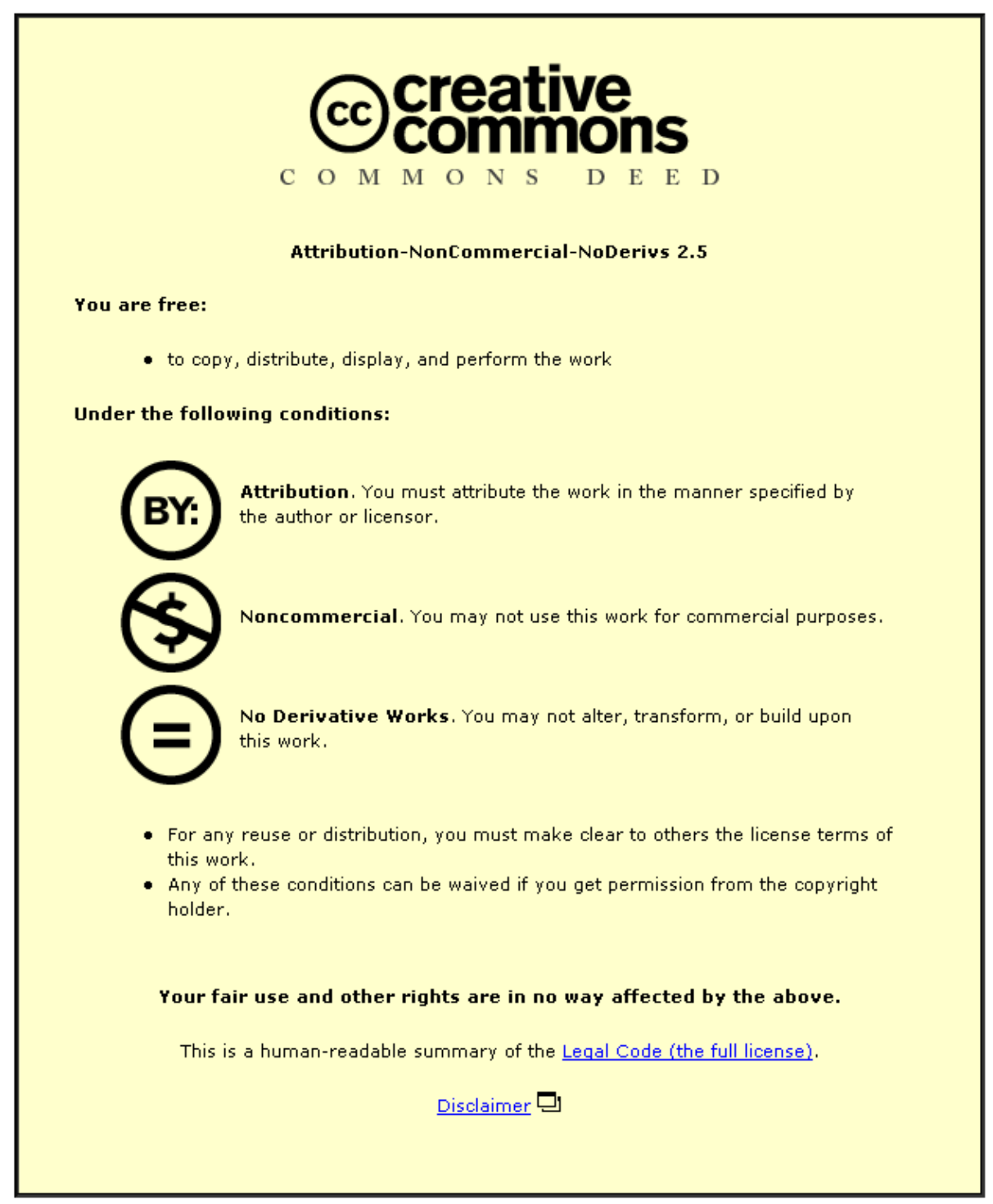

For the full text of this licence, please go to: http://creativecommons.org/licenses/by-nc-nd/2.5/ 


\title{
MODELLING AND EXPERIMENTAL STUDIES OF ALTERNATIVE \\ HEAT TREATMENTS IN STEEL 92 TO OPTIMISE LONG TERM \\ STRESS RUPTURE PROPERTIES
}

\author{
Y F Yin ${ }^{1}$, R G Faulkner ${ }^{1}$, P F Morris ${ }^{2}$ and P D Clarke ${ }^{2}$ \\ 1. IPTME, Loughborough University, Loughborough, England, LE11 3TU \\ 2. Corus UK, Swinden Technology Centre, Rotherham, England, S60 3AR
}

\begin{abstract}
The desire for power plant to give increased generating efficiency and decreased $\mathrm{CO}_{2}$ emission has led to considerable effort over the last 10-15 years, to develop ferritic-martensitic steels which can be used for steam temperatures up to about $650^{\circ} \mathrm{C}$. Examples are the addition of boron and increasing chromium content to $10 \sim 12 \mathrm{wt} \%$. However high chromium levels have led to problems with long term precipitate stability. One approach which has not been widely explored, is the use of novel heat treatments to optimise the pre-service microstructure to give the best long term creep rupture strength. Increased austenitising temperatures and lower tempering temperatures have been examined in Steel $92(9 \% \mathrm{Cr}, 0.5 \% \mathrm{Mo}, 2 \% \mathrm{~W})$ and have produced significant improvements in creep rupture strength at temperatures up to $650^{\circ} \mathrm{C}$ compared with material given a conventional heat treatment. This has been achieved without any loss in ductility compared with conventional heat treatments. Test data for durations in excess of 40,000 hours are presented.
\end{abstract}


Modelling of microstructure evolution based on Monte Carlo simulations has shown important differences 125 especially in the stability of grain boundary $\mathrm{M}_{23} \mathrm{C}_{6}$ and intragranular $\mathrm{MX}$ particles, between material with conventional and modified heat treatments. The model predictions are in good agreement with metallographic observations made on material before and after stress rupture testing. Continuum creep damage mechanics (CDM) modelling based on the microstructural evolution has also been applied to predict creep life of steel 92 and satisfactory agreement with creep rupture tests has been obtained.

\section{Keywords: Microstructural modelling, CDM modelling, Heat treatment, Creep strength, Ferritic steel, P/T92}

\section{Introduction}

Martensitic steels are preferable in conventional power plants to austenitic steels and nickel based alloys since they have much lower thermal expansion coefficients and high thermal conductivities, and are cheaper and easier to manufacture. ASTM A335-P92 most commonly known as steel P/T92 (or NF616), was developed in the early 1990s. ${ }^{1}$ This steel is now being widely used in many countries, and at the moment is regarded as the benchmark martensitic steel for power plants with operating temperatures in the range of 600 to $620^{\circ} \mathrm{C}$. Steel 92 is a $9 \% \mathrm{Cr}$ steel with Mo and $\mathrm{W}$ as the main alloying elements. The creep strength is controlled by the stability of the strengthening second phase particles, $\mathrm{M}_{23} \mathrm{C}_{6}$, Laves phase $\left(\mathrm{Fe}_{2}(\mathrm{Mo}, \mathrm{W})\right.$ and MX. At higher operating temperatures, for example $650^{\circ} \mathrm{C}$, the second phase particles coarsen more quickly resulting in decreased creep life.

Environmental regulation and the need for improved generation efficiency and smaller carbon footprints have led to growing interest in operating power plants at higher temperatures and/or 
pressures. Because there are no martensitic steels available for service temperatures above $625^{\circ} \mathrm{C}$, there are continuing efforts to design new ferritic-martensitic steels with higher creep strength. These have so far been unsuccessful. A different approach is to improve the performance of existing steels, for instance by changing the starting microstructure, as this significantly influences its subsequent evolution during exposure at service temperatures and hence the long-term creep properties. ${ }^{2,3}$ This can be achieved by changing the pre-service heat treatment. Corus UK has carried out some pioneering work in this area resulting in significant improvements in creep strength. ${ }^{4,5}$

In recent years, computer modelling and simulation have been widely used to assist new power plant alloy development and to gain a better understanding of the behaviour of existing alloys. The Monte Carlo based grain boundary and intra-granular precipitation kinetic simulation developed by Yin and Faulkner has proved to be very useful in assisting alloy development and can be used to study the effects of alloy composition and heat treatment on the microstructure and its evolution during ageing or service. ${ }^{6,7}$ This coupled with continuum creep damage mechanics (CDM) modelling has also shown that the stability of intergranular $\mathrm{M}_{23} \mathrm{C}_{6}$ and intragranular MX particles in power plant ferritic steels plays an important role in the long term creep behaviour of the material. ${ }^{6,8}$

This paper presents stress rupture test data and metallographic examination results of precipitate types and distributions for steel 92 with a novel pre-service heat treatment designed to optimise the creep strength. These data are compared with those of the conventionally heat treated material. Results of simulations of the nucleation, growth and coarsening of these particles for conventional and an alternative pre-service heat treatment are also reported and compared with experimental observations. CDM modelling results of creep rupture life of both alternatively and 
conventionally heat treated specimens are presented and compared with stress rupture test data and predictions for times up to 1000,000 hours are also reported.

\section{Experimental}

\subsection{Material}

The material examined corresponds to ASME-P92 $(9 \mathrm{Cr}-0.5 \mathrm{Mo}-1.8 \mathrm{~W}-\mathrm{VNb})$ produced as a $60 \mathrm{~kg}$ laboratory cast using air induction melting with the chemical composition given in Table 1. Also shown is the specified chemical composition range for steel NF616 (steel 92). ${ }^{1}$ The ingot was forged to $50 \mathrm{~mm}$ square bar and then rolled to $19 \mathrm{~mm}$ diameter round bar for the production of test samples. The final product was subjected to ultrasonic inspection to ensure that only sound material was used for the manufacture of test specimens.

\subsection{Heat Treatment.}

Generally, the heat treatment consists of a solution treatment followed by tempering. ASTM standard A213-T92 and A335-P92 require the solution treatment temperature to be a minimum of $1040^{\circ} \mathrm{C}$. However, temperatures of 1050 to $1070^{\circ} \mathrm{C}$ are the most common. Tempering is designed to create a highly stable microstructure, as close as possible to equilibrium, in order to minimise the rate of degradation during subsequent exposure at elevated temperature during service. A temperature within the range $730-810^{\circ} \mathrm{C}$ is recommended. Common practice for this type of steel is to use a temperature about $20^{\circ} \mathrm{C}$ below $\mathrm{Ac}_{1}$, typically $770-780^{\circ} \mathrm{C}$. The steel is designed to give a rupture life of $100,000 \mathrm{~h}$ at $600-620^{\circ} \mathrm{C}$, at a stress of $100 \mathrm{MPa}$. The alternative heat treatment investigated in the present work consisted of solution treatment at $1150^{\circ} \mathrm{C}$ followed by a double tempering at $660^{\circ} \mathrm{C}$, much lower than the recommended temperature range mentioned above. This was intended to produce a higher volume fraction and much finer dispersion of MX precipitates. Full details of the heat treatments are shown in Table 2. 


\subsection{Stress Rupture Testing.}

Specimens with alternative and conventional heat treatments were machined and stress rupture tests carried out according to BSEN10291:2000. For the samples which had undergone the alternative heat treatment stress rupture tests were carried out at temperatures from 600 to $675^{\circ} \mathrm{C}$, at stress levels designed to give target lives of up to 30,000 hours based on ECCC (European Creep Collaborative Committee) data for steel 92. ${ }^{9}$ The specimens with the conventional heat treatment were tested only at 600 and $650^{\circ} \mathrm{C}$.

\subsection{Hardness Testing.}

Vickers hardness testing with a $30 \mathrm{~kg}$ load was carried out on bakelite-mounted samples used for subsequent metallography. The hardness reported for each sample was the average of 3 indentations. Specimens with the alternative and conventional heat treatments were tested before and after stress rupture testing.

\subsection{Optical and Electron Metallography.}

Specimens were prepared for optical metallography and prior austenite grain size determination for material with alternative and conventional heat treatments. Carbon extraction replicas were taken from as-heat treated and failed stress rupture samples for quantitative analysis of precipitates using the transmission electron microscope. The carbon replicas obtained from the broken specimens were transverse sections near to the fracture zone.

\section{Modelling}

\subsection{Precipitation kinetics simulation}

Details of the Monte Carlo based precipitation kinetics simulation have been reported elsewhere ${ }^{6,8}$ However, a summary of the technique is provided below. The simulation is carried out in a representative body of the material termed the simulation cell, which includes both 
matrix and grain boundaries. Quench induced solute segregation to the grain boundaries is then calculated according to the non-equilibrium segregation model developed by Faulkner to give the solute concentration in grain boundaries of the simulation cell. ${ }^{10}$ The pre-service heat treatment and service (or test) durations at different temperatures are divided into small time intervals $\Delta t$. In each step, possible nucleation, growth and dissolution options are considered. Nucleation of precipitates is considered using classical theory and nuclei are generated both on grain boundaries and inside the grains according to the corresponding activation energies for nucleation. The growth or dissolution of a nucleated particle is determined by the solute concentration gradient around the particle. If the gradient is positive the particle grows, otherwise it dissolves. The gradient is determined by the average solute concentration, solute concentration at the surface of the particle and the average inter-particle spacing. Therefore, the increase in the volume of an intra-granular spherical particle $\Delta V$, in time interval $t \sim t+\Delta t$ is

$$
\Delta V=D_{V} S g \frac{\rho_{\theta}}{C_{\theta} \rho_{\theta}-C_{r} \rho_{\alpha}} \Delta t
$$

Where $S=4 \pi r^{2}$ is the surface area of the spherical particle with a radius of $r, g$ the solute concentration gradient at the interface, $D_{V}$ the volume diffusion coefficient, $\rho_{\theta}$ the density of the precipitate phase, $\rho_{\alpha}$ the density of the matrix, $C_{r}$ the solute concentration at the interface and $C_{\theta}$ the solute concentration in the precipitate phase. For grain boundary precipitates, solute atoms can migrate by both grain boundary diffusion and volume diffusion. Therefore, the increase in the volume of a grain boundary particle in time interval $t \sim t+\Delta t$ can be calculated using

$$
\Delta V_{G B}=\left(D_{V} S_{M} g_{M}+D_{G B} S_{G B} g_{G B}\right) \frac{\rho_{\theta}}{C_{\theta} \rho_{\theta}-C_{r} \rho_{\alpha}} \Delta t
$$

Where $S_{M}$ and $S_{G B}$ are the surface areas of the parts of grain boundary particle within the matrix and inside the grain boundary respectively and therefore $S_{M}+S_{G B}$ is the total surface area of the 
inter-granular particle, $D_{G B}$ is the grain boundary diffusion coefficient, $g_{M}$ and $g_{G B}$ are solute concentration gradients at the surface of the grain boundary particle from the matrix and along the grain boundary respectively and are calculated using average inter-particle spacing data. The process is then repeated for the required time duration.

Three main second phase particles were considered, $\mathrm{M}_{23} \mathrm{C}_{6}, \mathrm{MX}$ and Laves phase which are common and well known phases in $9 \mathrm{wt} \% \mathrm{Cr}$ ferritic steels. For $\mathrm{M}_{23} \mathrm{C}_{6}$ particles, $\mathrm{M}$ includes $\mathrm{Cr}$, Mo and $\mathrm{W}$ in the simulation. $\mathrm{MX}$ is treated as $\mathrm{V}(\mathrm{C}, \mathrm{N})$ and Laves phase has a composition of $(\mathrm{W}$, $\mathrm{Mo}, \mathrm{Nb})(\mathrm{Fe}, \mathrm{Cr})_{2}$. The solubilities of different elements in steel 92 are calculated using the thermodynamic phase calculation software and database package MTDATA developed by the National Physical Laboratory, Teddington, UK. ${ }^{11}$ The parameters used are listed in Table 3. The simulation follows the exact pre-service heat treatment conditions. This pre-service heat treatment is followed by an ageing at 600 and $650^{\circ} \mathrm{C}$ for up to $1,000,000 \mathrm{~h}$ to facilitate comparison with existing and future experimental data from creep tested samples.

\subsection{CDM Modelling}

The CDM modelling in this study is based on Dyson's approach ${ }^{12}$ and has been developed by the authors to take the advantage of the microstructural evolution data from the Monte Carlo based precipitation kinetics simulations. ${ }^{8}$ The technique provides a unified framework for predictions of creep behaviour by considering different possible creep damage mechanisms using the following equation for creep rate, $\dot{\varepsilon}$ :

$$
\dot{\varepsilon}=\frac{\dot{\varepsilon}_{0}}{\left(1-D_{d}\right)\left(1-D_{S}\right)} \sinh \left[\frac{\sigma(1-H)}{\sigma_{0}\left(1-D_{P}\right)\left(1-D_{N}\right)}\right]
$$

The two parameters $\dot{\varepsilon}_{0}$ and $\sigma_{0}$ are related to temperature

$$
\dot{\varepsilon}_{0}=\dot{\varepsilon}_{0}^{\prime} \exp \left(1-\frac{Q_{d / j}}{R T}\right)
$$




$$
\sigma_{0}=\sigma_{o, m}\left\{1-\exp \left[-\frac{\Delta H}{R T_{S}}\left(\frac{T_{S}}{T}-1\right)\right]\right\}
$$

where $\dot{\varepsilon}_{0}^{\prime}$ is a constant, $Q_{d / j}$ is the combined activation energy for diffusion and jog formation, $T_{S}$ is the solvus temperature when $\sigma_{0}=0$ and $\Delta H$ is the enthalpy of solution. $\sigma_{o, m}$ is the maximum value of $\sigma_{0}$ when $T=0$, and is directly proportional to the Orowan stress. Four creep damage mechanisms are considered in Equation (3). They are thermally induced creep damage due to solution depletion from the matrix, $D_{S}$, and due to particle coarsening, $D_{P}$, and strain induced creep damage due to grain boundary cavity nucleation and growth, $D_{N}$, and due to multiplication of mobile dislocations, $D_{d}$. The four damage parameters are defined as follows.

$$
\begin{gathered}
D_{S}=1-\frac{\bar{C}_{t}}{C_{0}} \\
D_{P}=1-\frac{P_{0}}{P_{t}} \\
D_{N}=A \varepsilon^{B} \\
D_{d}=1-\frac{\rho_{0}}{\rho_{t}}
\end{gathered}
$$

where $P_{0}$ and $P_{t}$ are inter-particle spacings at times $t=0$ and $t=t$ respectively, $C_{0}$ and $C_{t}$ are concentrations of solute which play a role in the solution hardening in the material at $t=0$ and $t=t, \rho_{0}$ and $\rho_{t}$ are dislocation densities at $t=0$ and $t=t$, and $A$ and $B$ are temperature dependent material constants. Inter-particle spacing and solute concentration at any time are the outputs of the Monte Carlo precipitation kinetics simulation and therefore can be directly used in the CDM modelling. Creep damage due to multiplication of mobile dislocations is not considered here. Parameters used in this study for CDM modelling of steel 92 are listed in Table 4 for temperatures of 600 and $650{ }^{\circ} \mathrm{C}$.

\section{Results}

\subsection{Microstructural evolution}

\subsubsection{Experimental results}

Microstructure was determined before and after stress rupture testing at $650^{\circ} \mathrm{C}$ and $92 \mathrm{MPa}$. Stress rupture tests at $600{ }^{\circ} \mathrm{C}$ are still continuing and there is no failed specimen available for 
microstructure investigation. Optical and Transmission Electron Microscopy (TEM) were used to compare the initial microstructure and the evolution of precipitates. Fig. 1 shows optical micrographs of the as-heat treated specimens. These were tempered martensite but the alternative heat treatment gave a prior austenite grain size significantly larger $(40 \mu \mathrm{m})$ than the conventional heat treatment $(12 \mu \mathrm{m})$ owing to the higher solution heat treatment temperature.

Fig. 2 shows bright field TEM images of carbon extraction replicas from the specimens before the stress rupture test. The specimens with the alternative heat treatment, 2a-c, had a larger grain size, and the distribution of precipitates was more homogeneous than in the steel 92 with conventional heat treatment, $2 \mathrm{~d}-\mathrm{f}$. The latter showed intense precipitation at the prior austenite grain boundaries but much less intense precipitation at the martensite lath boundaries. Clusters of precipitates close to the prior austenite grain boundaries were also observed in the conventionally heat treated sample, whereas in the sample with the alternative heat treatment the precipitation was more evenly distributed between the prior austenite and the martensite lath boundaries (Fig. 2). Particle analyses indicated the presence of $\mathrm{M}_{23} \mathrm{C}_{6},(\mathrm{Cr}, \mathrm{V}, \mathrm{Nb},) \mathrm{X}$, and $\mathrm{NbX}$ precipitates. A quantitative assessment of these precipitates revealed that the mean particle size of $\mathrm{M}_{23} \mathrm{C}_{6}$ in the sample with the alternative treatment was slightly larger $(127 \mathrm{~nm})$ than that observed in the sample with conventional treatment $(110 \mathrm{~nm})$ (Table 5). However, the mean particle size of $(\mathrm{Cr}, \mathrm{V}, \mathrm{Nb},) \mathrm{X}$ in conventionally treated material was more than twice $(29 \mathrm{~nm})$ that observed for the alternative heat treatment $(11 \mathrm{~nm})$. In addition, the number of MX particles per unit area was significantly higher (298 particles $\left./ \mu \mathrm{m}^{2}\right)$ in the sample with the alternative treatment than in the sample with conventional treatment $\left(12\right.$ particles $\left./ \mu \mathrm{m}^{2}\right)$.

A failed stress rupture sample was examined after testing at $650^{\circ} \mathrm{C}$ and $92 \mathrm{MPa}$. Fig. 3 shows TEM images of carbon extraction replicas of the creep exposed specimens. These showed 
similar trends to the uncrept samples. However in addition to the particle species observed in the uncrept samples, Sigma phase, Laves phase $\left(\mathrm{Fe}_{2} \mathrm{Mo}\right)$ and Chi-phase, were found. Quantitative particle analysis revealed the average particle size of $\mathrm{M}_{23} \mathrm{C}_{6}$, Sigma phase, Laves phase and Chiphase was larger $(260 \mathrm{~nm})$ for the specimen with the alternative heat treatment than for the sample with the conventional treatment $(198 \mathrm{~nm})$. The opposite was observed for the $(\mathrm{Cr}, \mathrm{Nb}, \mathrm{V}) \mathrm{X}$ type particles. The mean particle size of $\mathrm{MX}$ particles after stress rupture testing was $26 \mathrm{~nm}$ with the alternative heat treatment and $34 \mathrm{~nm}$ with the conventional treatment. The number of MX particles per unit area was about twice as high in the sample with the alternative heat treatment (Table 5).

\subsubsection{Precipitation simulation results}

Figs. 4-5 show the simulation predicted particle size and inter-particle spacing of the three main phases in samples creep tested at $650{ }^{\circ} \mathrm{C}$ after conventional (Fig. 4(a), Fig. 5(a)) and alternative (Fig. 4(b) and Fig. 5(b)) heat treatment as a function of time, together with experimental measurements before and after the stress rupture test. In both figures, the time from 0 to $2 \mathrm{~h}$ for the conventional and from 0 to $6 \mathrm{~h}$ for the alternative heat treatment is the tempering process. Fig. 4 compares the modelled particle size for three main second phase particles, namely $\mathrm{M}_{23} \mathrm{C}_{6}$, MX and Laves phase in steel 92 with the conventional and alternative pre-service heat treatments and subsequently stress rupture tested at $650^{\circ} \mathrm{C}$. There is no measured size of Laves phase. The agreement between the modelled and measured particle sizes of both $\mathrm{M}_{23} \mathrm{C}_{6}$ and $\mathrm{MX}$ is very good both at the end of the pre-service heat treatment and after creep rupture. The modelling also shows that $\mathrm{M}_{23} \mathrm{C}_{6}$ particles are inter-granular. The inter-particle spacing, which is important to the creep properties of the material is shown in Fig. 5. The experimental interparticle spacing is determined from the number of particles per unit area of observation listed in Table 5. This is a two dimensional approximation of a three dimensional problem and the number of particles are strictly not in a surface plane but in a small volume of a slice of the 
material. Therefore, the value is only an approximation of inter-particle spacing. Taking account of this consideration, the predictions are in reasonably good agreement with experimental measurements for both conventional and alternative heat treated materials. In summary, the precipitation kinetics modelling results are in good agreement with experimental measurements. It should be noted that Laves phase forms earlier in the case of alternative heat treatment due to the lower tempering temperatures used. In the case of conventional heat treatment, Laves phase does not form during tempering.

\subsubsection{Comparison of the predictions for the conventional and alternative heat treatment}

Fig. 6 shows the predicted particle size of $\mathrm{M}_{23} \mathrm{C}_{6}$ and $\mathrm{MX}$ particles in steel 92 with the conventional and alternative pre-service heat treatment and aged at $650{ }^{\circ} \mathrm{C}$ for up to $1,000,000$ hours. $\mathrm{M}_{23} \mathrm{C}_{6}$ particles in steel 92 with the alternative heat treatment are larger than those with conventional heat treatment (Fig. 6 (a)), in agreement with experimental observations (Fig. 4 (a)). This is partly attributed to the higher solution treatment temperature used in the alternative heat treatment. It is well known that impurities in steels can segregate to grain boundaries via non-equilibrium segregation when quenched from the solution treatment temperature and the segregation level increases sharply with increasing temperature. The segregation of $\mathrm{Cr}$ to grain boundaries during quenching enhances the saturation level of $\mathrm{Cr}$ at those boundaries and therefore increases the driving force for the nucleation of grain boundary Cr-rich particles, such as $\mathrm{M}_{23} \mathrm{C}_{6}$. Another effect of this increased segregation of $\mathrm{Cr}$ to grain boundaries is the increase of $\mathrm{Cr}$ concentration gradient to the surface of $\mathrm{Cr}$-rich particles along grain boundaries with the resultant faster growth. Higher solution treatment temperatures may also result in higher concentration of carbon in the matrix by dissolving more $\mathrm{NbC}$. This will increase the supply of carbon to the carbides and may result in larger particle sizes. The stability of $\mathrm{M}_{23} \mathrm{C}_{6}$ particles are similar in steel 92 with conventional and alternative heat treatment as there is no appreciable difference in the rate of coarsening between the two cases. 
The characteristics of MX phase in these two heat treatment conditions are considerably different (Fig. 6(b)). Firstly, a much finer size distribution of MX particles is formed when applying the alternative pre-service heat treatment due to the much lower tempering temperature used, which promotes the nucleation and gives much lower growth rates. Secondly, the coarsening rate of MX particles in the case of the alternative heat treatment is much faster than that in the case of conventional heat treatment be 3cause the MX particles in the alternatively heat treated material are more finely spaced than after conventional heat treatment. This results in a greater solute concentration gradient between adjacent particles thus increasing the coarsening rate. Despite this the VN particles in alternatively treated specimens remain much smaller than in the conventionally heat treated alloy even after exposure for hundreds of thousand hours. This effect is even more marked at lower temperatures, such as $600{ }^{\circ} \mathrm{C}$.

\subsection{Stress Rupture Life}

\subsubsection{Stress rupture testing}

Table 6 shows the stress rupture programme, and its status at the time of preparation of the paper (February 2008). At $600^{\circ} \mathrm{C}$ the specimens with the conventional heat treatment broke between $82-91 \%$ of the aim lives indicating that the cast used in this work did not have unusually good stress rupture properties. The specimens with the alternative pre-service heat treatment have exceeded the aim lives significantly. The specimen subjected to $172 \mathrm{MPa}$ had reached more than 13 times the 3,000 hour aim without failing. At $625^{\circ} \mathrm{C}$ no conventionally heat treated samples were tested. For the alternative heat treatment a sample with an aim life of 3,000 hours failed after 16,967 hours, more than five times the aim life. The 10,000 hour aim sample failed after 26,280 hours. The 30,000 hour aim sample had not failed after $>29,000$ hours. At $650^{\circ} \mathrm{C}$ the samples with conventional treatment failed at $49-81 \%$ of the aim lives, whereas the alternative heat treatment samples gave failure lives of 6,179 and 12,089 hours for aims of 3,000 
and 10,000 hours respectively. At $675^{\circ} \mathrm{C}$ one specimen with the conventional treatment was tested and it failed at about $80 \%$ of the aim life. For the alternative heat treatment the specimen subjected to $81 \mathrm{MPa}$ exceeded the 3,000 h aim by 1,192 hours. The specimen with a target life of $10,000 \mathrm{~h}$ failed after 10,625 hours. The ductilities of the samples with the alternative heat treatment were similar to or higher than those of the equivalent conventionally treated samples. Therefore, the improvement in creep life of the alternatively heat treated samples does not sacrifice any creep ductility.

Fig. 7 shows a Larson-Miller plot of the stress rupture data of both conventionally and alternatively heat treated steel 92 specimens, together with the ECCC mean line for comparison. The conventionally heat treated samples generally have similar or slightly shorter creep life, but the alternatively heat treated samples have longer creep life compared to the ECCC mean line. The improvement is most marked for the lower temperature higher stress tests, but even at $675^{\circ} \mathrm{C}$ there was still some improvement for rupture lives out to 10,000 hours.

\subsubsection{CDM modelling}

Creep rupture life of both alternatively and conventionally heat treated specimens have been calculated using CDM modelling with parameters shown in Table 4 based on the microstructural evolution information presented in Section 3 and by setting the fracture true strain to $20 \%$. The change of parameter $\sigma_{o, m}$ from the value for conventional to that for alternative heat treatment is based on a simple consideration. $\sigma_{o, m}$ is directly proportional to the Orowan stress and therefore is inversely proportional to the initial inter-particle spacing. According to the precipitation kinetics simulation, the initial inter-particle spacing is $184 \mathrm{~nm}$ in the case of conventional heat treatment and $60 \mathrm{~nm}$ in the case of alternative heat treatment. Therefore, a factor of 3 is applied to the value of $\sigma_{o, m}$. As this is the inter-particle spacing at the end of pre-service heat treatment, 
the values of $\sigma_{o, m}$ are independent of the service (or testing) temperatures and therefore are same for 600 and $650{ }^{\circ} \mathrm{C}$. The values of parameter $A$ and $B$ for grain boundary cavitation were determined using a similar approach to that used in reference, ${ }^{8}$ i.e. by fitting the CDM modelling to the ECCC mean line under conventional heat treatment conditions.

The results of CDM modelling are shown in Fig. 8, together with experimental test results of this study (triangles for conventional heat treatment and circles for alternative heat treatment) and the ECCC mean data (squares). The lines are CDM modelling results: solid lines for conventional heat treatment, dashed lines (labelled model alternative 1) for alternative heat treatment using parameters in Table 4. The dotted lines (labelled model alternative 2) in Fig. 8 are also for alternative heat treatment, but with slightly higher values of $B$ for cavity nucleation, increased from 1.01 to 1.03 at $600{ }^{\circ} \mathrm{C}$ and from 1.04 to 1.06 at $650{ }^{\circ} \mathrm{C}$. This is to take into account the fact that $\mathrm{M}_{23} \mathrm{C}_{6}$ grain boundary particles are bigger in the case of alternatively heat treated specimens and grain boundary cavities often nucleate at the interface of large grain boundary particles and the grain boundaries.

From Fig. 8, the CDM modelling results of conventionally heat treated steel 92 are in good agreement with experimental tests and the ECCC data at both 600 and $650{ }^{\circ} \mathrm{C}$. At $600{ }^{\circ} \mathrm{C}$ (Fig. 8a), the lines for alternative heat treatment shifts to the right considerably, indicating much improved of creep rupture life. The two continuing stress rupture tests fall between the CDM predictions for conventional and alternative heat treatment and the model predicts the two specimens have considerable remanent life. Fig. 8a also shows that the alternatively heat treated material has better creep resistance up to a very long service time than the conventionally treated one. 
The improvement of creep properties at $650{ }^{\circ} \mathrm{C}$ is much less as indicated by both $\mathrm{CDM}$ modelling and experimental testing, especially at lower stresses and longer rupture lives. This is because the finer distribution of MX particles coarsens much faster at higher temperatures as predicted by the precipitation simulations. The long term creep behaviour is the effect of the combination of the characteristics of the initial particle dispersion and the stability of the particles. In the alternative case, the initial creep resistance is higher but the stability of the particles is lower due to smaller inter-particle spacing as compared to the conventional case. At lower temperatures, particle stability is high and the initial creep resistance plays a more important role. At higher temperatures, thermodynamic stability of the particles is a more important issue and therefore results in a smaller overall improvement of creep resistance. In fact, the line of alternative heat treatment with adjusted parameter $B$ (which is in good agreement with experimental test results) crosses over the line for conventional heat treatment in Fig. 8b at a creep life of between 100,000 and 200,000 hours. This corresponds to an applied stress of about $60 \mathrm{MPa}$. Therefore, CDM modelling suggests that the creep life of alternatively heat treated samples at stresses lower than $60 \mathrm{MPa}$ and at temperatures higher than $650{ }^{\circ} \mathrm{C}$ is actually shorter than the conventionally heat treated samples. This implies that the creep resistance can be optimised for different application stresses and temperatures by varying preservice heat treatment. But to carry out such optimisation experimentally is deemed too costly and time consuming and can best be realised by the combination of experimental testing and associated computer modelling.

\section{Discussion}

The microscopic assessment of the as-heat treated samples indicated that, as expected, a higher solution treatment temperature resulted in a larger prior austenite grain size, but also led to a higher volume fraction of finer $(\mathrm{Cr}, \mathrm{Nb}, \mathrm{V}) \mathrm{X}$ particles. This is presumably due to more complete 
dissolution of primary carbides and VX particles in austenite, which on cooling re-precipitate as a finer dispersion due to the lower tempering temperature. This is in agreement with work reported by Janovec et al., ${ }^{13}$ who indicated that particle size increases with tempering temperature. Vanadium was the principal metallic element present in these fine MX particles. It has been found that $\mathrm{Nb}(\mathrm{C}, \mathrm{N})$ precipitates do not dissolve completely during solution treatment even at a temperature of $1145^{\circ} \mathrm{C}$ for Steel $92 .{ }^{14}$ However, the higher the solution treatment temperature, the higher the volume fraction of precipitates that dissolve in the austenite. In the absence of precipitation this improves the solid solution strengthening which is important for long-term creep resistance. ${ }^{15}$ It also reduces the $\mathrm{M}_{\mathrm{S}}$ temperature of the steel, leading to an increase in martensite stability and strength after cooling. ${ }^{16,}{ }^{17}$ Low solution treatment temperatures result in a loss of creep rupture strength due to the finer austenite grain size and incomplete carbide dissolution. ${ }^{18}$ Excessive solution treatment temperatures are not only difficult to achieve due to furnace limitations, but may lead to $\delta$-ferrite formation preventing the production of a fully martensitic microstructure with a consequent loss of strength. The alternative and conventional heat treatments had similar volume fractions of $\mathrm{M}_{23} \mathrm{C}_{6}$ particles. The fine dispersion of MX precipitates produced by the alternative heat treatment is more effective in locking dislocations when the steel is exposed at high temperature leading to an increase in creep strength. Although the grain size after the alternative treatment was significantly larger, the precipitates were more evenly distributed between the prior austenite and the martensite lath boundaries than in the material with the conventional heat treatment. The stress rupture results showed that the alternative heat treatment produced a significant improvement in creep properties. This was more pronounced at lower temperatures and at the time of writing (February 2008) extends to test durations in excess of 41,000 hours. For the limited data available in the test programme so far rupture ductilities were not reduced in the samples which had been given the low temperature temper. However further work is required to 
explore the effects on other properties such as Charpy toughness which is important particularly during construction of commercial scale power plant.

The Monte Carlo based precipitation kinetics simulation has successfully predicted the evolution of the main second phase particles in steel 92 and has shown clear microstructural differences in the materials with conventional and alternative pre-service heat treatment. The predictions show that $\mathrm{M}_{23} \mathrm{C}_{6}$ particles in the alternatively heat treated material are much bigger than those in the material with conventional heat treatment. Although the long term coarsening rates of the particles are similar in both materials, the bigger size of the grain boundary $\mathrm{M}_{23} \mathrm{C}_{6}$ in the alternatively heat treated material may have adverse effects on the creep properties by promoting grain boundary cavity nucleation at later stages of creep. However, this may have much less effect than the strengthening due to the much finer MX phase in the material. The predictions show that the densely distributed fine MX phase remains much smaller in the alternatively treated material than in the conventionally treated one within the normal service life time of common power plant components, even though the coarsening rate is higher particularly in the early stages of creep exposure.

CDM modelling based on the Monte Carlo based precipitation kinetics simulation has been successful in predicting creep rupture life of conventionally heat treated steel 92 and in demonstrating the effects of the pre-service heat treatment. The improvement of creep resistance by alternative heat treatment is dependent on the application stresses and temperatures and the higher the temperature, the less the improvement. However the improvements in creep life at current and just above current service temperatures are significant. At higher temperatures because the finer distribution of the main strengthening second phase particle, vanadium-rich MX, in steel 92 coarsens much faster at higher temperatures as a result of increased diffusivity. 


\section{Summary}

The purpose of the work was to explore the use of novel pre-service heat treatments for steel 92 as a way of improving its creep strength. Results show that by using a higher solution treatment temperature and a lower tempering temperature significant increases in creep rupture strength can be obtained at temperatures in excess of $620^{\circ} \mathrm{C}$, the upper limit of the normal service temperature range for this alloy. The lower temperature temper produced a finer dispersion of intra-granular MX particles than found in conventionally heat treated material. From the limited data available the improved creep rupture strength was obtained without a significant reduction in rupture ductility. However additional work is required to ensure that other important properties such as toughness have not been compromised. Recent attempts to extend the upper limit of service temperatures for ferritic-martensitic creep resistant steels have focused on making compositional modifications to existing alloys and have been unsuccessful in producing significant improvements over the creep rupture strength of steel 92, currently the best existing commercially available alloy. The current work indicates that a more fruitful area for examination is to produce modifications to the base the microstructure by the use of novel heat treatment cycles. The work presented in the current paper has indicated that significant improvements in rupture strength can be obtained by this route. A more extensive and systematic test programme is needed to explore this approach more fully.

Microstructural evolution modelling is in very good agreement with experimental measurements in predicting the size and spacing of the main second phase particles in steel 92 . The capability of the modelling to show the effect of heat treatment on the microstructural evolution to times in excess of the service life time of common power plant components makes it very useful in future studies of this kind. CDM modelling based on the microstructural evolution simulation predicts rupture lives in good agreement with experimental data. In addition, CDM modelling 
demonstrates that it is possible to optimise the creep resistance of steel 92 for different application stresses and temperatures by optimising the balance between the initial microstructure and its thermodynamic stability through varying the pre-service heat treatment cycle. Future work on the design of pre-service heat treatment to optimise creep properties of steel 92 will be aided greatly by microstructure and CDM modelling.

Acknowledgements The authors would like to thank Mr M Baker for his help in the creep laboratory at CRD\&T Swinden Technology Centre and to Miguel Yescas who, whilst at Swinden Technology Centre, was involved in the design of the heat treatment modifications. Finally thanks go to the TSB for funding the modelling work (Programme Project H0101B).

\section{References}

[1] Nippon Steel Corporation, Data Package for NF616 Ferritic Steel (9Cr-0.5Mo-1.8Mo-NbV), 2nd edition. March 1994.

[2] Kimura K., Seki K., Toda Y., and Abe F. Development of high strength $15 \mathrm{Cr}$ ferritic creep resistant steel with addition of tungsten and cobalt. ISIJ International, 41 Supplement, 2000, S101-S105.

[3] R. L. Klueh, N. Hashimoto and P.J. Maziasz, New nano-particle-strengthened ferritic/martensitic steels by conventional thermo-mechanical treatment, Journal of Nuclear Materials, 367-370, 2007, 48-53.

[4] M A Yescas and P F Morris, Improved Creep Resistance of Steel 92 by the Use of Modified heat treatments, Proceedings of Conference: Creep and Fracture in High Temperature Components - Design and Life Assessment Issues, ECCC Creep Conference, London, September 2005, 143. 
[5] Y. F. Yin, R. G. Faulkner, P. F. Morris and P. D. Clarke: Microstructural modelling and experimental studies of alternative heat treatments in steel 92 to optimise long term stress rupture properties, Parsons' 2007, 453-464.

[6] Y. F. Yin and R. G. Faulkner: Simulations of precipitation in ferritic steels, Mater. Sci. Technol., 19, 2003, 91-98.

[7] Y. F. Yin and R. G. Faulkner: Modelling the effects of alloying elements on precipitation in ferritic steels, Mater. Sci. Eng. A, 344A, 2003, 92-102.

[8] Y. F. Yin and R. G. Faulkner: Continuum damage mechanics modelling based on simulations of microstructural evolution kinetics, Mater. Sci. Technol., 22, 2006, 929-936.

[9] European Creep Collaborative Committee, ECCC Data Sheets, 1999.

[10] R. G. Faulkner: Segregation to Boundaries and Interfaces in Solids, Int. Mater. Rev., 41,1996, 198-208.

[11] R. H. Davies, A. T. Dinsdale, J. A. Gisby, J. A. J. Robinson, S. M. Martin, MTDATA Thermodynamic and Phase Equilibrium Software from the National Physical Laboratory, CALPHAD 26, 2002, 229-271.

[12] B. Dyson, J. Pres. Ves. Technol., 2000, 122, (3), 281-296.

[13] Janovec J., Vyrostkova A., and Svoboda M., Influence of tempering temperature on stability of carbide phases in $2.6 \mathrm{Cr}-0.7 \mathrm{Mo}-0.3 \mathrm{~V}$ steel with various carbon content, Metallurgical Transactions, A 25A, 1994, 267-275.

[14] Nickel H. Ennis P. and Wachter O. The effect of heat treatment on the microstructure and properties of 9Cr-0.5Mo-1.8W steel. AM. Soc. Met/JSME. Pressure Vessels and Piping Conference 1995; 237-243.

[15] Murugananth M., and Bhadeshia H. K. D. H., Components of the creep strength of welds, Trends in Welding, (2002).

[16] Petty E. R. Martensite; Fundamentals and technology. Longman Group Ltd 1970; 
[17] Igarashi M., Muneki S., and Abe F. Microstructure control of martensitic phase matrix in advanced ferritic steels for USC boilers to achieve long term stability. Proc. Liege Conf. On Materials for Advanced Power Engineering, edited by J. Lecomet-Beckers, F. Schubert and P.J. Ennis, Forshungzentrum, Julich GmbH. 1998; 637-646.

[18] Barraclough D. R. and Gooch D. J. Effect of inadequate heat treatment on creep strength of 12C-Mo-V steel. Materials Science and Technology, 1, 1985, 961-967. 


\section{CAPTIONS TO TABLES AND FIGURES}

Table 1. Chemical compositions of steel 92 used in the present work (wt\%, Fe balance)

Table 2. Alternative and conventional heat treatments investigated.

Table 3. Parameters used in the precipitation kinetics simulation.

Table 4. Parameters used in CDM modelling.

Table 5. Quantitative analysis of precipitates.

Table 6. Creep test programme and results for Steel 92.

Figure 1: Optical micrographs of specimens with (a) alternative and (b) conventional heat treatments.

Figure 2: Bright field TEM images of carbon replicas, (a), (b) and (c) alternative heat treatment, and (d), (e) and (f) conventional heat treatment.

Figure 3: Bright field TEM images of carbon replicas (a) alternative heat treatment after 12,089 hours at $650^{\circ} \mathrm{C}$ and $92 \mathrm{MPa}$, showing $\mathrm{M}_{23} \mathrm{C}_{6}$ marked 29-33, and (b) conventional heat treatment after 6,109 hours at $650^{\circ} \mathrm{C}$, showing Laves phase marked 121 .

Figure 4. Comparison of modelled and measured particle size for (a) conventional and (b) alternative heat treatments. The ageing temperature is $650{ }^{\circ} \mathrm{C}$.

Figure 5. Comparison of modelled and measured inter-particle spacings of second phase particles for (a) conventional and (b) alternative heat treatments. The ageing temperature is 650 ${ }^{\circ} \mathrm{C}$. 
Figure 6: Comparison of particle size and its evolution of (a) $\mathrm{M}_{23} \mathrm{C}_{6}$ and (b) $\mathrm{MX}$ in steel 92 with the conventional and alternative pre-service heat treatment. The ageing temperature in the modelling is $650{ }^{\circ} \mathrm{C}$.

Figure 7. Larson-Miller plot of experimental stress rupture data for both conventional and alternatively heat treated steel 92, together with the ECCC data.

Figure 8. CDM predictions of creep rupture life for steel 92 at 600 (a) and $650 \mathrm{oC}$ (b) with conventional and alternative heat treatment, together with experimental test results of this study and the ECCC data. 
Table 1: Chemical composition of Steel 92 used in the present work (wt\%)

\begin{tabular}{|c|c|c|c|c|c|c|c|c|c|c|c|c|c|c|}
\hline & $\mathrm{C}$ & Si & Mn & $P$ & $S$ & $\mathrm{Cr}$ & Mo & $\mathrm{Ni}$ & Al & B & $N$ & $\mathrm{Nb}$ & V & W \\
\hline $\begin{array}{c}\text { Steel } \\
92\end{array}$ & 0.11 & 0.33 & 0.48 & 0.012 & 0.005 & 9.05 & 0.46 & 0.22 & 0.007 & 0.0056 & 0.053 & 0.065 & 0.22 & 1.85 \\
\hline $\begin{array}{c}\text { Data } \\
\text { Package }\end{array}$ & $\begin{array}{c}0.07 \\
- \\
0.13\end{array}$ & $=0.5$ & $\begin{array}{c}0.30 \\
- \\
0.60\end{array}$ & $=0.02$ & $=0.01$ & $\begin{array}{l}8.50 \\
-9.5\end{array}$ & $\begin{array}{c}0.30 \\
- \\
0.60\end{array}$ & $=0.4$ & $=0.04$ & $\begin{array}{c}0.001 \\
- \\
0.006\end{array}$ & $\begin{array}{c}0.03 \\
- \\
0.07\end{array}$ & $\begin{array}{c}0.04 \\
- \\
0.09\end{array}$ & $\begin{array}{c}0.15 \\
- \\
0.25\end{array}$ & $\begin{array}{c}1.5 \\
- \\
2.0\end{array}$ \\
\hline
\end{tabular}

Table 2: Alternative and conventional heat treatments investigated.

\begin{tabular}{|c|c|c|c|c|c|c|}
\hline \multirow{2}{*}{ Heat treatment } & \multicolumn{2}{|c|}{ Solution Treatment } & \multicolumn{5}{c|}{ Tempering } \\
\cline { 2 - 7 } & $\begin{array}{c}\text { Temperature } \\
\left({ }^{\circ} \mathrm{C}\right)\end{array}$ & $\begin{array}{c}\text { Time } \\
(\text { Hours })\end{array}$ & $\begin{array}{c}\text { Temperature } \\
\left({ }^{\circ} \mathrm{C}\right)\end{array}$ & $\begin{array}{c}\text { Time } \\
(\text { Hours })\end{array}$ & $\begin{array}{c}\text { Temperature } \\
\left({ }^{\circ} \mathrm{C}\right)\end{array}$ & $\begin{array}{c}\text { Time } \\
(\text { Hours })\end{array}$ \\
\hline Alternative & 1150 & 1 & 660 & 3 & 660 & 3 \\
\hline Conventional & 1060 & 1 & 780 & 2 & - & - \\
\hline $\begin{array}{c}\text { ASTM standard } \\
\text { A213-T92 and } \\
\text { A335-P92 }\end{array}$ & $1040 \mathrm{~min}$ & - & $730-810$ & - & - & - \\
\hline
\end{tabular}

Note: All specimens were air-cooled from both solution treatment and tempering temperatures. 
Table 3: Parameters used in the precipitation kinetics simulation

\begin{tabular}{|c|c|c|c|c|c|}
\hline \multicolumn{5}{|c|}{ Lattice parameter $(a, \mathrm{~nm})$ : } & 0.2866 \\
\hline \multicolumn{5}{|c|}{ Matrix molar density $\left(\rho_{\alpha}, \mathrm{mol} \mathrm{m}^{-3}\right)$ : } & 110546 \\
\hline \multicolumn{5}{|c|}{ Melting point $\left(T_{M}, \mathrm{~K}\right)$ : } & 1860 \\
\hline \multicolumn{5}{|l|}{ Lath width $(d, \mathrm{~nm})$ : } & 500 \\
\hline \multicolumn{5}{|c|}{ Grain boundary width $(\delta, \mathrm{nm})$ : } & 1 \\
\hline \multicolumn{5}{|c|}{ Grain boundary energy $\left(\gamma_{G B}, \mathrm{~J} \mathrm{~m}^{-2}\right)$ : } & 0.23 \\
\hline \multicolumn{5}{|c|}{ Vacancy formation energy $\left(E_{f}, \mathrm{eV} /\right.$ atom $)$ : } & 1.4 \\
\hline \multirow{4}{*}{ Particle properties } & Phase & \multicolumn{2}{|c|}{ Contact angle (degree) } & \multicolumn{2}{|c|}{ Interfacial energy $\left(\mathrm{J} \mathrm{m}^{-2}\right)$} \\
\hline & $\mathrm{M}_{23} \mathrm{C}_{6}$ & \multicolumn{2}{|c|}{57} & \multicolumn{2}{|c|}{0.67} \\
\hline & $\mathrm{VN}$ & \multicolumn{2}{|c|}{90} & \multicolumn{2}{|c|}{0.87} \\
\hline & $\begin{array}{l}\text { Laves } \\
\text { phase }\end{array}$ & \multicolumn{2}{|c|}{90} & \multicolumn{2}{|c|}{0.34} \\
\hline \multirow{10}{*}{$\begin{array}{l}\text { Diffusion } \\
\text { coefficients }\end{array}$} & Elements & \multicolumn{2}{|c|}{ Volume diffusion } & \multicolumn{2}{|c|}{ GB diffusion } \\
\hline & & $\mathrm{D}_{0}\left(\mathrm{~m}^{2} \mathrm{~s}^{-1}\right)$ & $\mathrm{Q}(\mathrm{eV})$ & $\mathrm{D}_{0}\left(\mathrm{~m}^{2} \mathrm{~s}^{-1}\right)$ & $\mathrm{Q}(\mathrm{eV})$ \\
\hline & $\mathrm{Cr}$ & 0.00085 & 2.49 & 502 & 2.94 \\
\hline & $\mathrm{W}$ & 0.0002 & 2.555 & 502 & 2.94 \\
\hline & Mo & $6.63 \times 10^{-5}$ & 2.3265 & 502 & 2.94 \\
\hline & $\mathrm{C}$ & $6.2 \times 10^{-7}$ & 0.834 & $6.2 \times 10^{-9}$ & 0.417 \\
\hline & $\mathrm{V}$ & 0.000305 & 2.483 & 502 & 2.94 \\
\hline & $\mathrm{N}$ & $1 \times 10^{-6}$ & 0.83865 & & \\
\hline & $\mathrm{Nb}$ & 0.53 & 3.57 & 502 & 2.94 \\
\hline & $\mathrm{Fe}$ & 0.00085 & 2.49 & 502 & 2.94 \\
\hline
\end{tabular}


Table 4 Parameters used in CDM modelling.

\begin{tabular}{llll}
\hline Parameter & Unit & \multicolumn{2}{c}{ Value } \\
\cline { 3 - 4 } & & $\mathbf{6 0 0}^{\mathbf{0}} \mathbf{C}$ & $\mathbf{6 5 0}^{\mathbf{0}} \mathbf{C}$ \\
\hline$\dot{\varepsilon}_{0}^{\prime}$ & $\mathrm{s}^{-1}$ & 7400 & 7400 \\
$\mathrm{Q}_{\mathrm{dj}}$ & $\mathrm{kJ} \mathrm{mol}^{-1}$ & 300 & 300 \\
$\sigma_{o, m}$ & $\mathrm{MPa}$ & $33(99)^{*}$ & $33(99)^{*}$ \\
$\Delta \mathrm{H} / \mathrm{RT}_{\mathrm{S}}$ & $/$ & 0.35 & 0.35 \\
$T_{S}$ & $\mathrm{~K}$ & 1350 & 1350 \\
$A$ & $/$ & 1.5 & 2.5 \\
$B$ & $/$ & 1.01 & 1.04 \\
\hline
\end{tabular}

*values are different for conventionally and alternatively heat treated specimens. Those in parentheses are for alternative heat treatment. 
Table 5: Quantitative analysis of precipitates

\begin{tabular}{|c|c|c|c|}
\hline Specimen & Type of particle & $\begin{array}{c}\text { No particles } \\
\text { per } \mu \mathrm{m}^{2}\end{array}$ & $\begin{array}{c}\text { Mean particle size } \\
\mathrm{nm}\end{array}$ \\
\hline \multirow{2}{*}{$\begin{array}{l}\text { As-heat treated: } \\
\text { alternative heat treatment }\end{array}$} & $\mathrm{M}_{23} \mathrm{C}_{6}$ & 5.0 & 127 \\
\hline & $(\mathrm{Cr}, \mathrm{Nb}, \mathrm{V}) \mathrm{X}$ & 298 & 11.0 \\
\hline \multirow{2}{*}{$\begin{array}{l}\text { As-heat treated: } \\
\text { conventional heat treatment }\end{array}$} & $\mathrm{M}_{23} \mathrm{C}_{6}$ & 6.0 & 110 \\
\hline & $(\mathrm{Cr}, \mathrm{Nb}, \mathrm{V}) \mathrm{X}$ & 12 & 29 \\
\hline \multirow[t]{2}{*}{$\begin{array}{l}\text { After stress rupture test: } \\
\text { alternative heat treatment }\end{array}$} & $\begin{array}{c}\mathrm{M}_{23} \mathrm{C}_{6}, \text { Sigma } \\
\text { phase, Chi phase, } \\
\text { Laves phase }\end{array}$ & 1.3 & 260 \\
\hline & $(\mathrm{Cr}, \mathrm{Nb}, \mathrm{V}) \mathrm{X}$ & 12.0 & 26 \\
\hline \multirow[t]{2}{*}{$\begin{array}{l}\text { After stress rupture test: } \\
\text { conventional heat treatment }\end{array}$} & $\begin{array}{c}\mathrm{M}_{23} \mathrm{C}_{6}, \text { Sigma } \\
\text { phase, Chi phase, } \\
\text { Laves phase } \\
\end{array}$ & 1.7 & 198 \\
\hline & $(\mathrm{Cr}, \mathrm{Nb}, \mathrm{V}) \mathrm{X}$ & 6.4 & 34 \\
\hline
\end{tabular}


Table 6 Creep test programme and resuls for Steel 92

\begin{tabular}{|c|c|c|c|c|c|c|}
\hline \multirow{2}{*}{$\begin{array}{c}\text { Temperature } \\
\left({ }^{\circ} \mathrm{C}\right)\end{array}$} & \multirow{2}{*}{$\begin{array}{l}\text { Stress } \\
(\mathrm{MPa})\end{array}$} & \multirow{2}{*}{$\begin{array}{c}\text { Aim } \\
\text { Duration } \\
\text { (h) }\end{array}$} & \multicolumn{2}{|c|}{ Alternative HT } & \multicolumn{2}{|c|}{ Conventional HT } \\
\hline & & & Life (h) & $\mathrm{RA} \%$ & Life (h) & RA\% \\
\hline \multirow{4}{*}{600} & 187 & 1,000 & - & - & 856 & 70 \\
\hline & 172 & 3,000 & $41,100 u b$ & - & 2,722 & 66 \\
\hline & 156 & 10,000 & $41,000 u b$ & - & 8,222 & 45 \\
\hline & 140 & 30,000 & - & - & 11,992 & 35 \\
\hline \multirow{4}{*}{625} & 140 & 3,000 & 16,967 & 17 & - & - \\
\hline & 122 & 10,000 & 26,280 & 15 & - & - \\
\hline & 107 & 30,000 & $29,000 u b$ & - & - & - \\
\hline & 122 & 1000 & - & - & 807 & 58 \\
\hline \multirow{2}{*}{650} & 110 & 3,000 & 6,179 & 35 & 1,734 & 35 \\
\hline & 92 & 10,000 & 12,089 & 27 & 6,109 & 15 \\
\hline & 78 & 30,000 & - & - & 14,729 & 8 \\
\hline \multirow{2}{*}{675} & 81 & 3,000 & 4,192 & 25 & 2,456 & 20 \\
\hline & 66 & 10,000 & 10,625 & 12 & - & - \\
\hline
\end{tabular}



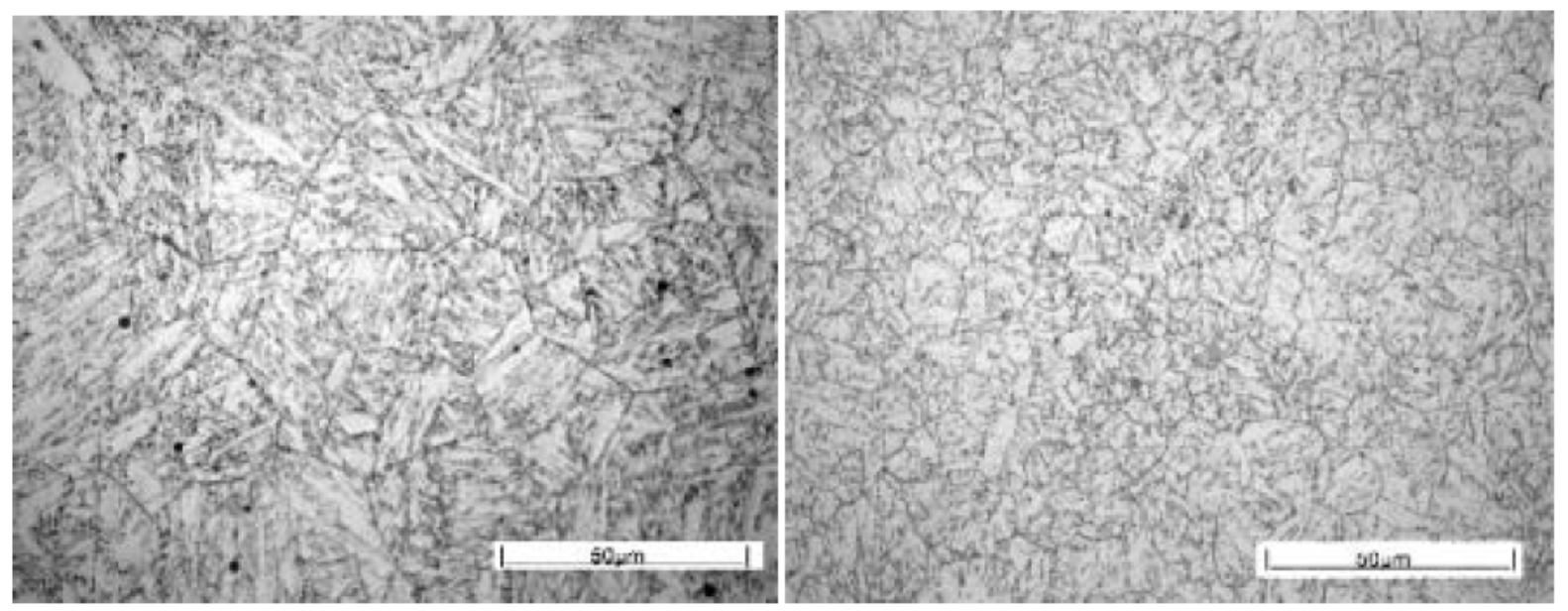

Figure 1: Optical micrographs of specimens with (a) alternative and (b) conventional heat treatments. 

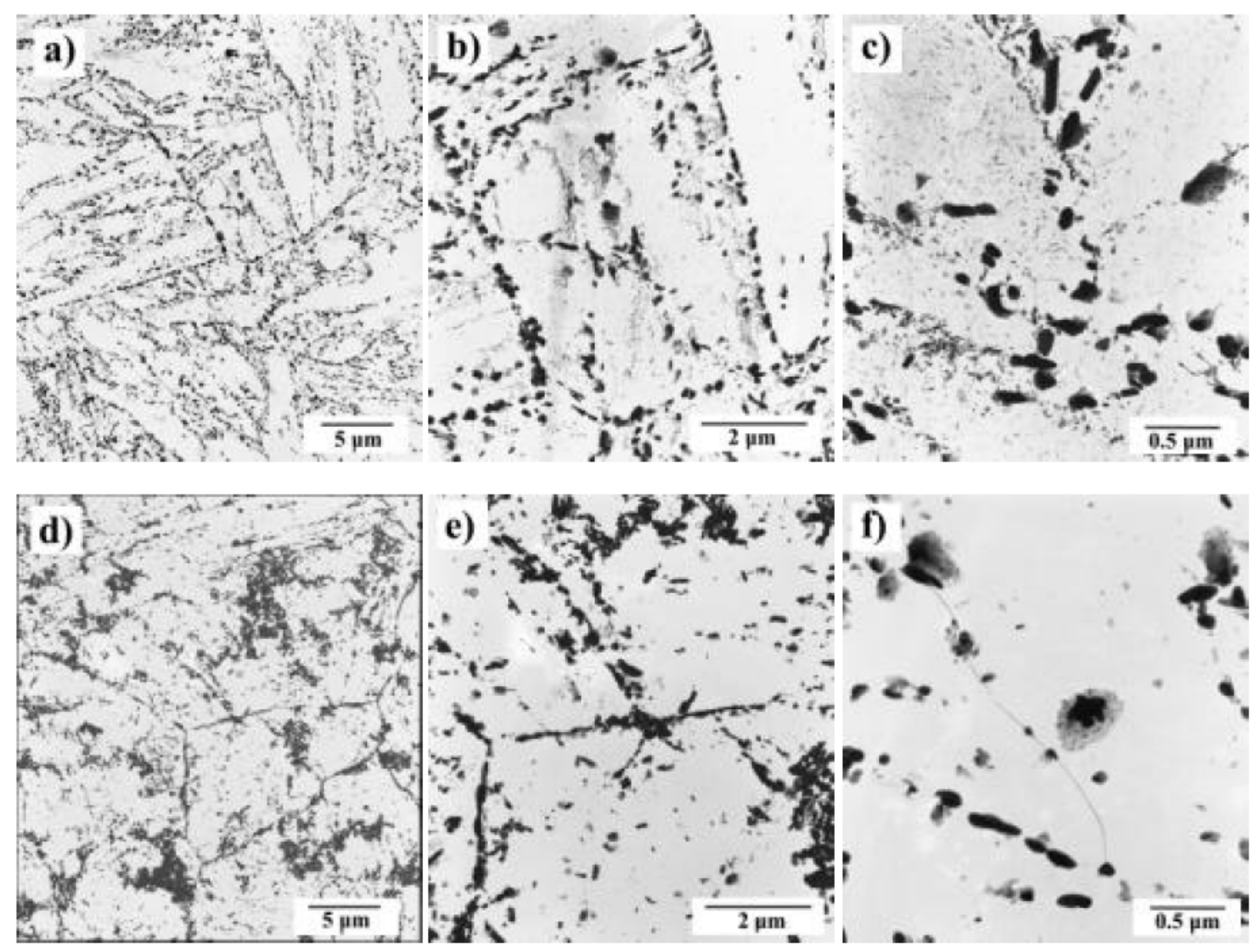

Figure 2: Bright field TEM images of carbon replicas, (a), (b) and (c) alternative heat treatment, and (d), (e) and (f) conventional heat treatment. 

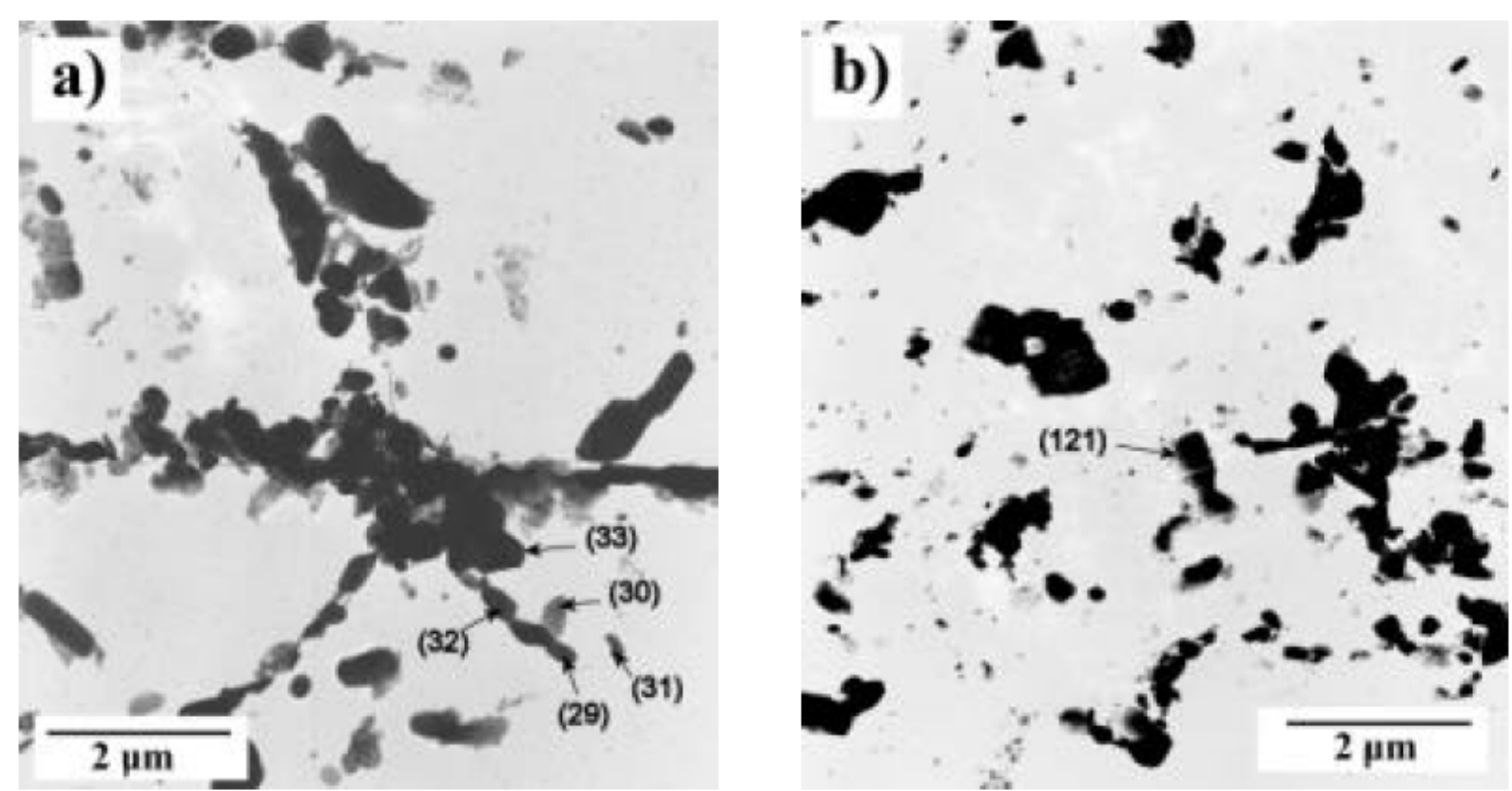

Figure 3: Bright field TEM images of carbon replicas (a) alternative heat treatment after 12,089 hours at $650^{\circ} \mathrm{C}$ and $92 \mathrm{MPa}$, showing $\mathrm{M}_{23} \mathrm{C}_{6}$ marked 29-33, and (b) conventional heat treatment after 6,109 hours at $650^{\circ} \mathrm{C}$, showing Laves phase marked 121. 

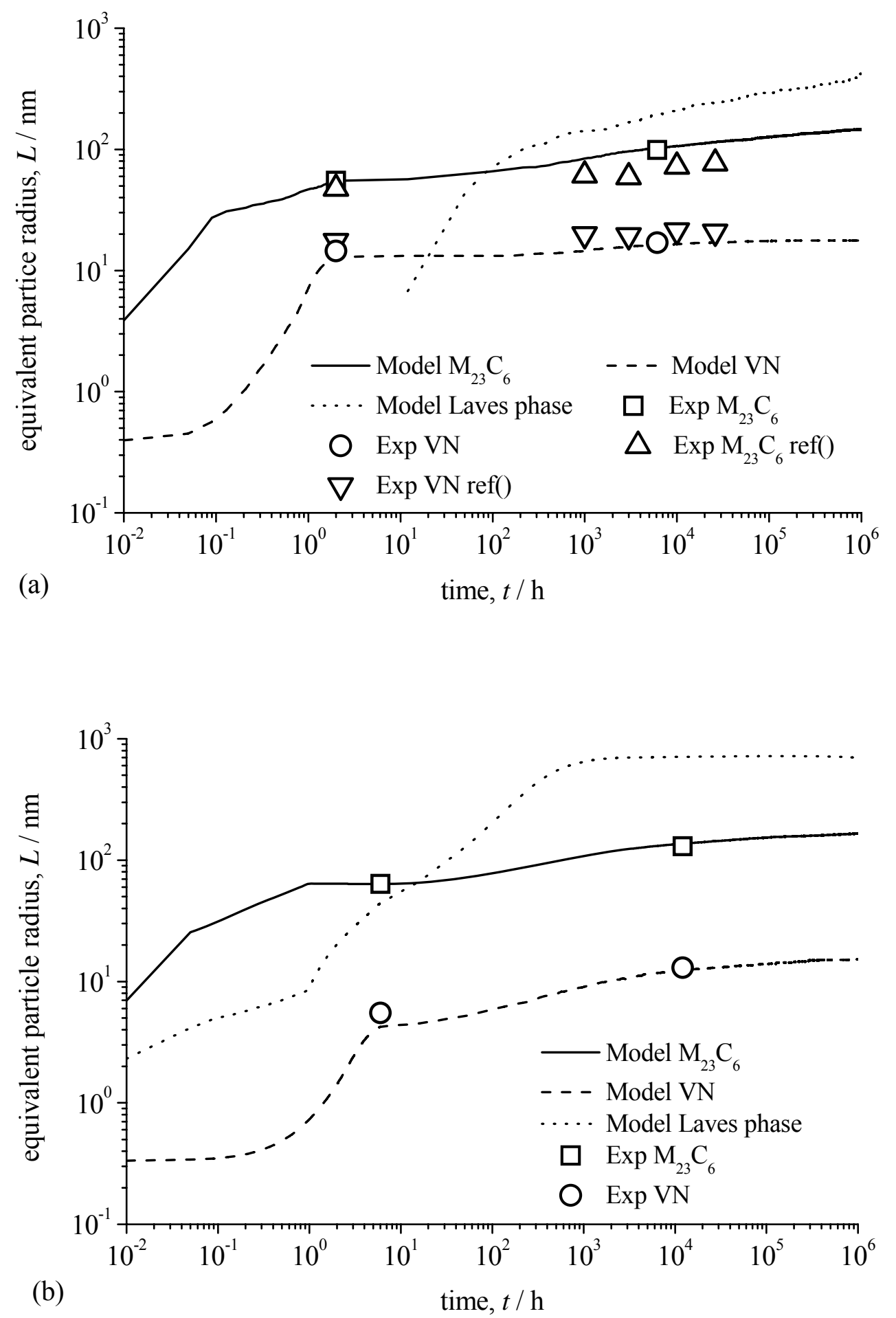

Figure 4. Comparison of modelled and measured particle size for (a) conventional and (b) alternative heat treatments. The ageing temperature is $650{ }^{\circ} \mathrm{C}$. 


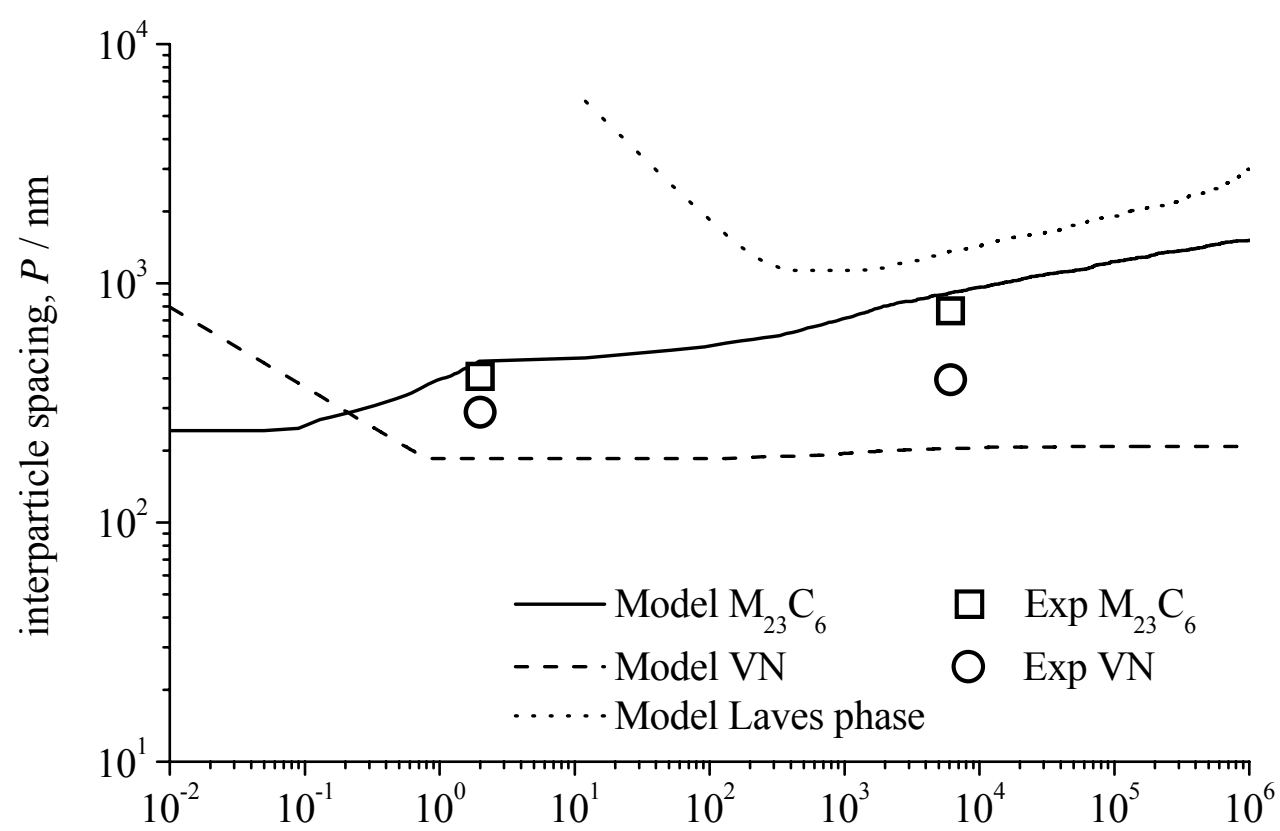

(a)

time, $t / \mathrm{h}$

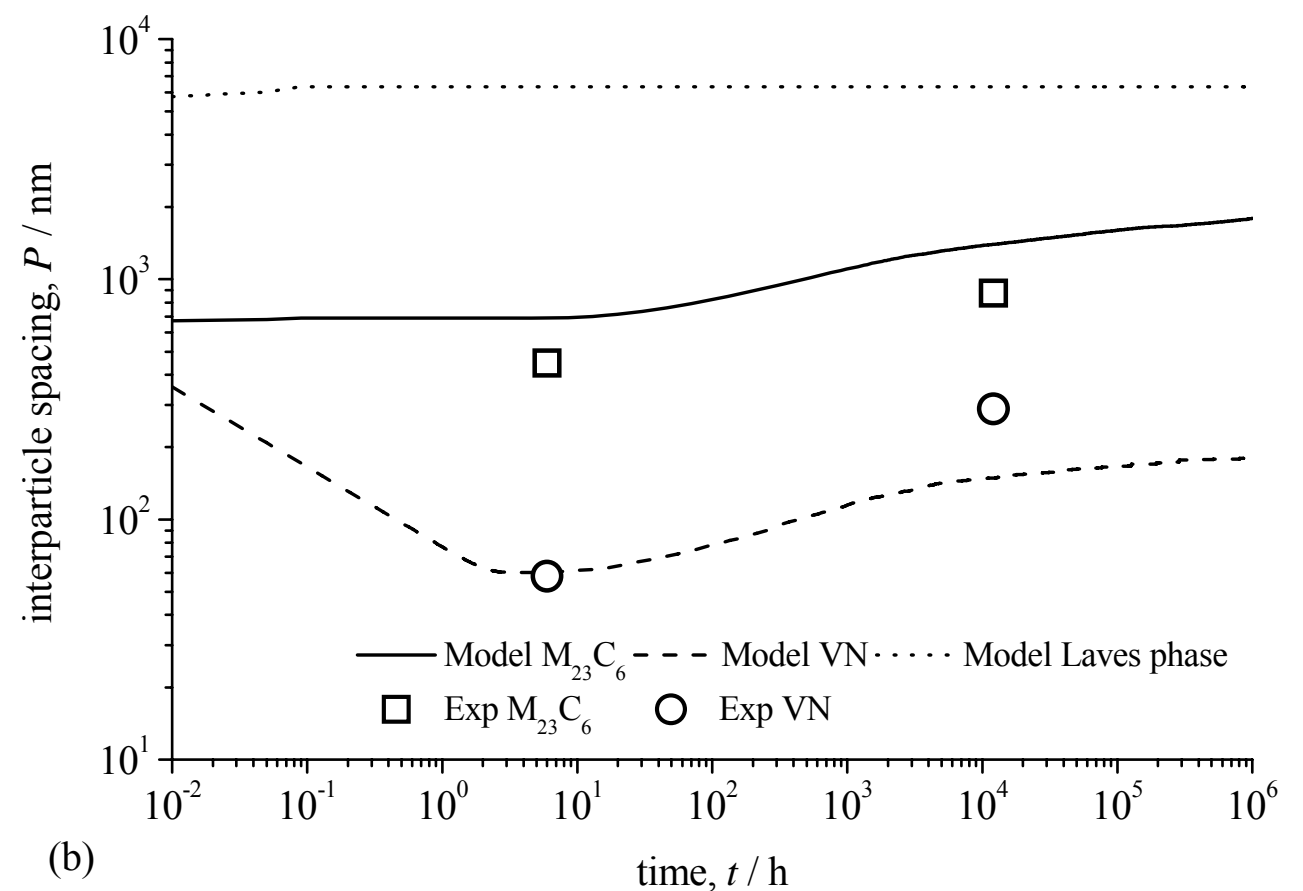

Figure 5. Comparison of modelled and measured inter-particle spacings of second phase particles for (a) conventional and (b) alternative heat treatments. The ageing temperature is $650{ }^{\circ} \mathrm{C}$. 


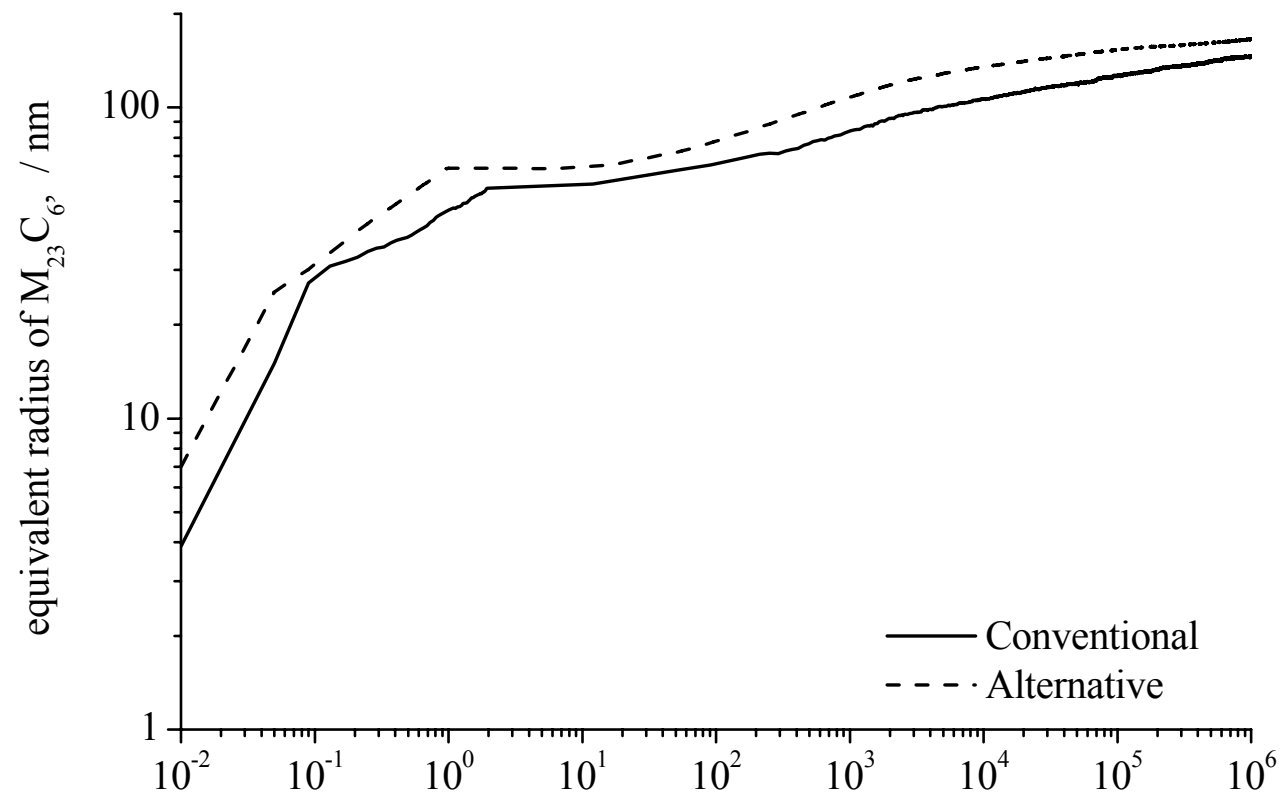

(a)

time, $t / \mathrm{h}$

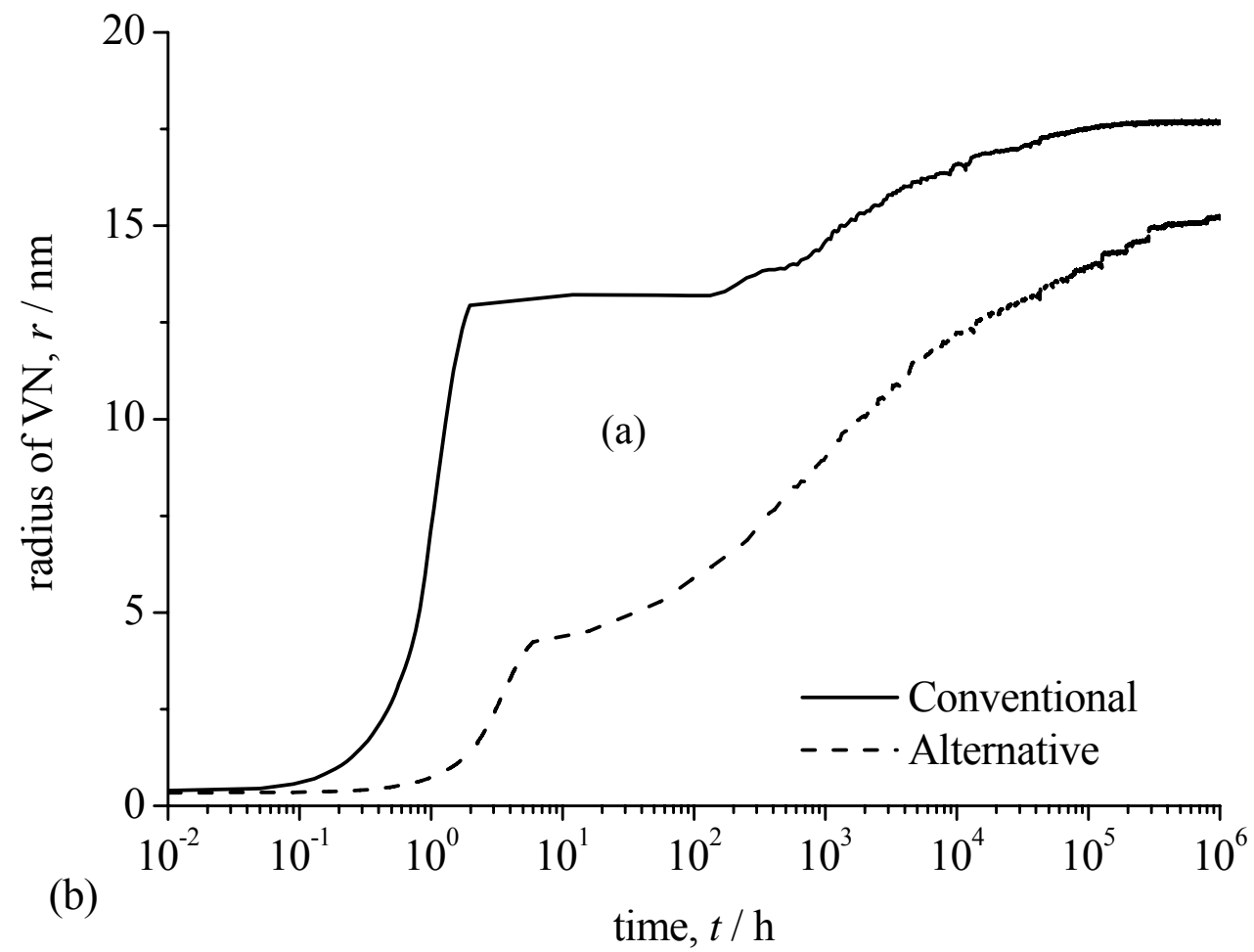

Figure 6: Comparison of particle size and its evolution of (a) $\mathrm{M}_{23} \mathrm{C}_{6}$ and (b) $\mathrm{MX}$ in steel 92 with the conventional and alternative pre-service heat treatment. The ageing temperature in the modelling is $650{ }^{\circ} \mathrm{C}$. 


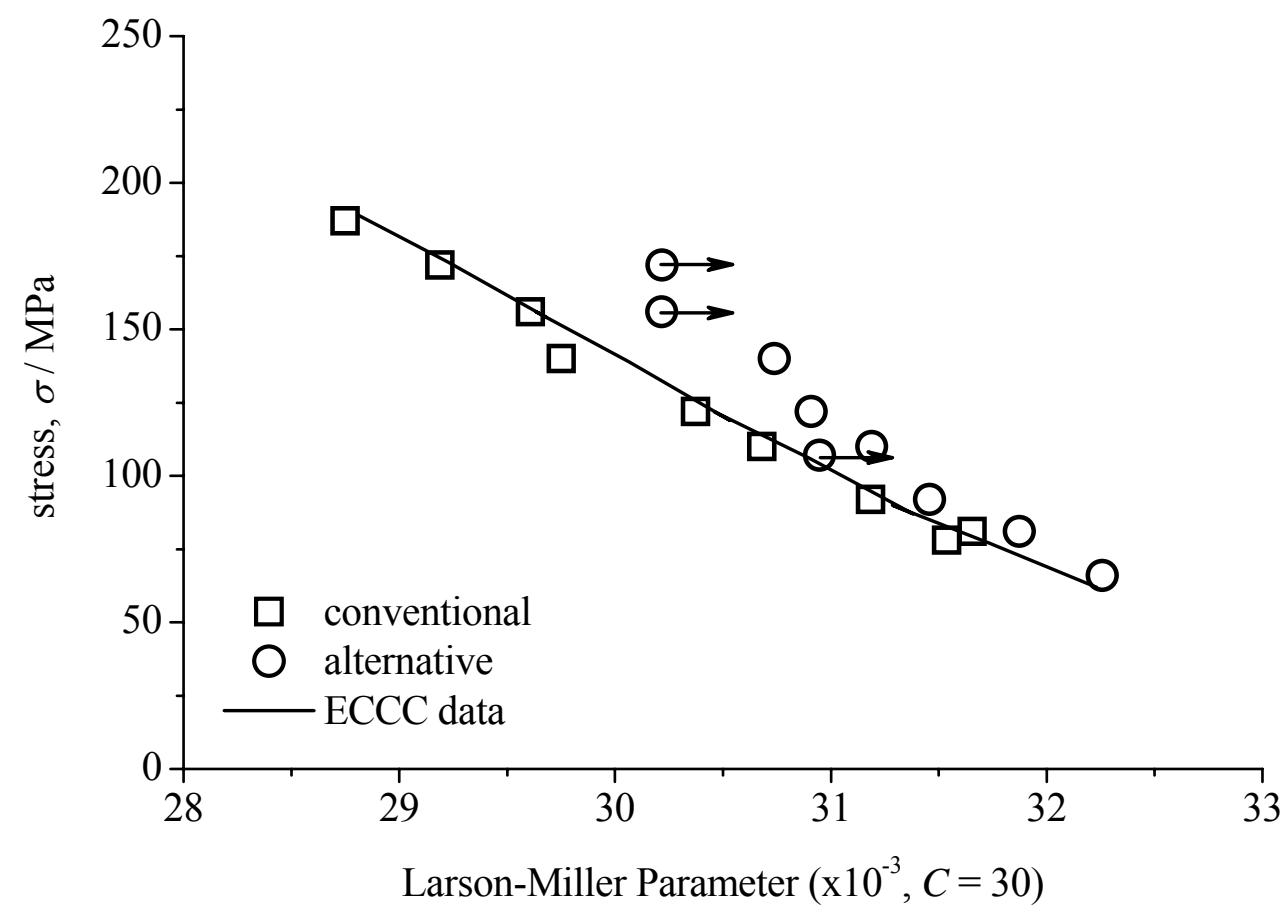

Figure 7. Larson-Miller plot of experimental stress rupture data for both conventional and alternatively heat treated steel 92, together with the ECCC data. 


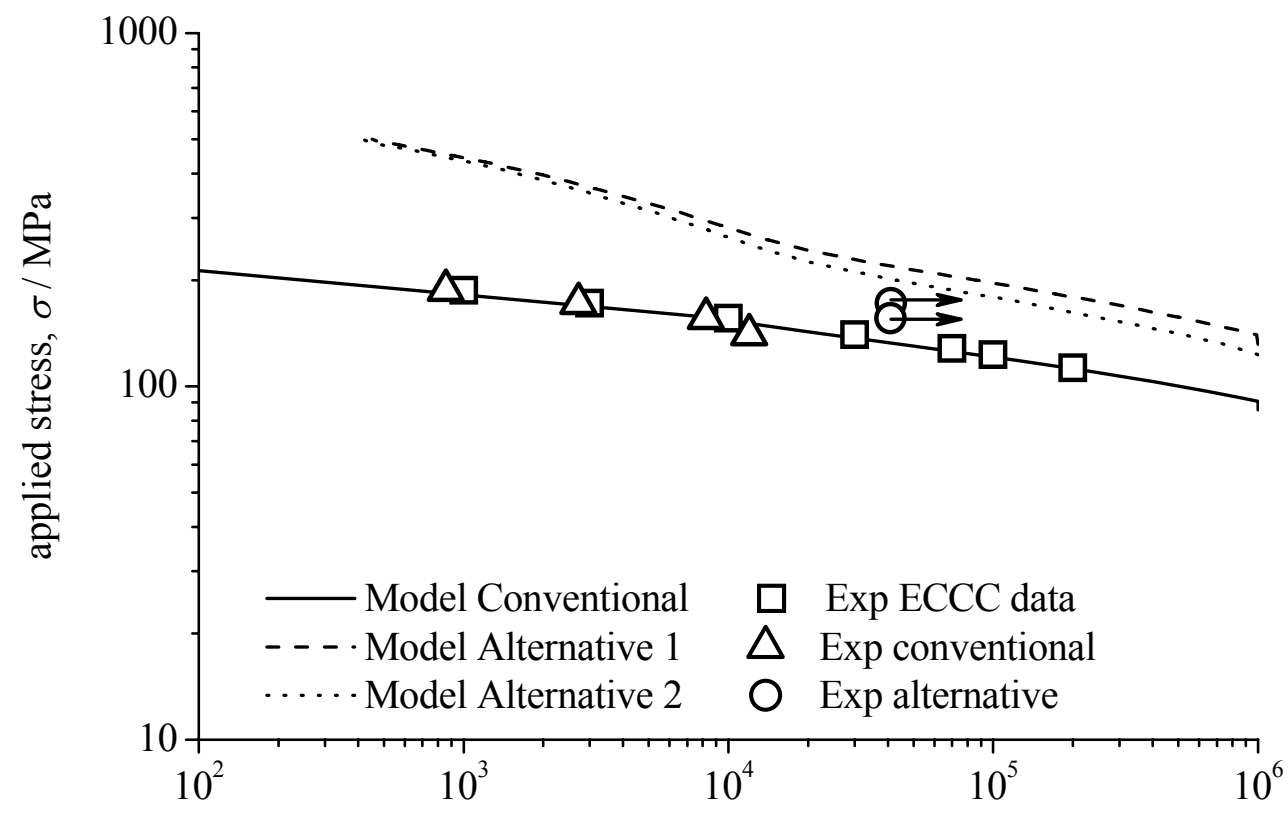

(a)

rupture life, $t_{r} / \mathrm{h}$

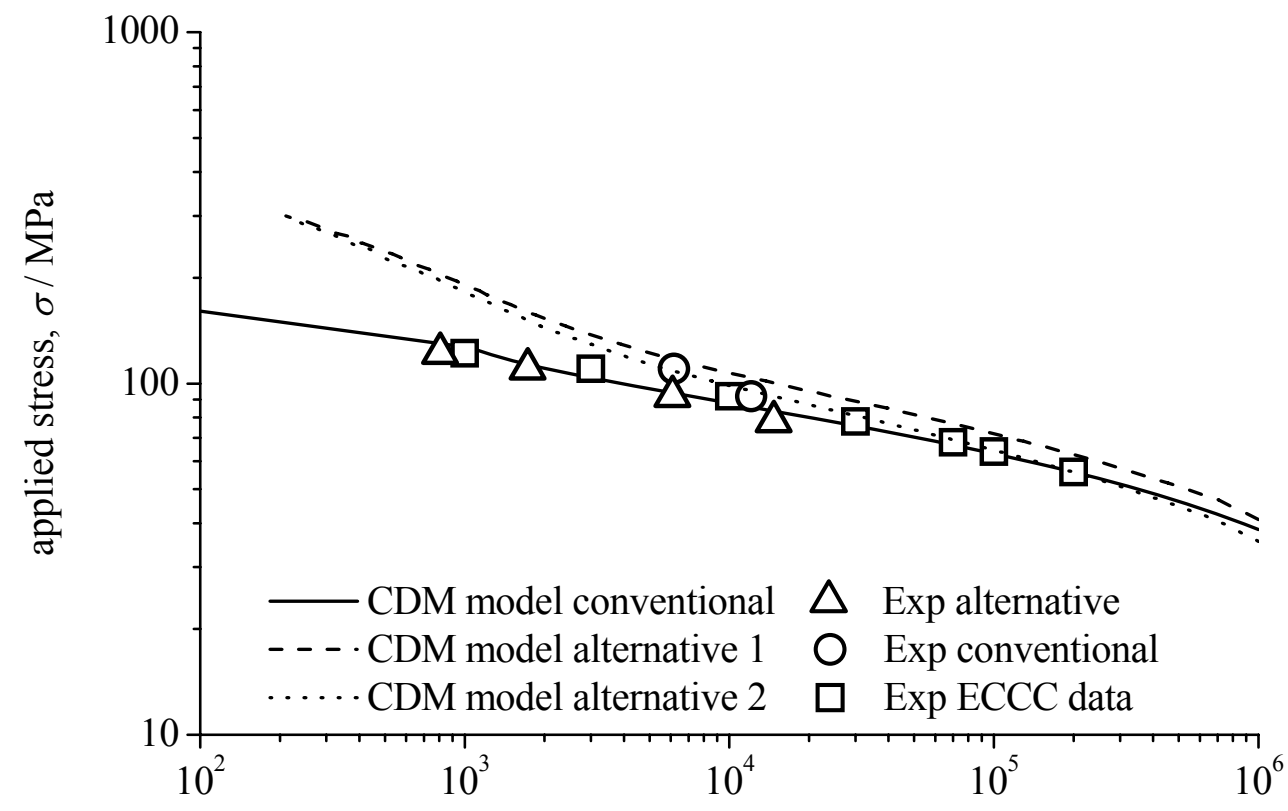

(b)

rupture life, $t_{\mathrm{r}} / \mathrm{h}$

Figure 8. CDM predictions of creep rupture life for steel 92 at 600 (a) and $650 \mathrm{oC} \mathrm{(b)} \mathrm{with} \mathrm{conventional} \mathrm{and} \mathrm{alternative} \mathrm{heat} \mathrm{treatment,}$ together with experimental test results of this study and the ECCC data. 